\title{
Yarn hairiness parameterization using a coherent signal processing technique
}

\author{
Vítor Carvalho ${ }^{\mathrm{a}, *}$, Paulo Cardoso ${ }^{\mathrm{b}}$, Michael Belsley ${ }^{\mathrm{b}}$, \\ Rosa M. Vasconcelos ${ }^{\mathfrak{c}}$, Filomena O. Soares ${ }^{\mathrm{a}}$ \\ " Universidude do Minho, Department Electrónica Industrial, Campus de Azurém, 4800-058 Gumarâes, Portugal \\ 'Universidade do Minho, Department Fisica, Campus de Azurém, 4800).058 Guimarāes. Portugal \\ c Universidade do Minho, Departmént Engenharia Têxil, Campus de Azurém, 4800-058 Guimarães, Portuzal \\ Received 30 September 2006; received in revised form 29 December 2006; accepted 25 February 2007 \\ Available online 2 March 2007
}

\begin{abstract}
The aim of this paper is to present an automatic yarn hairiness parameterization method based on optical sensors. Hairiness measurements are performcd using a coherent signal processing technique for higher resolution. Using this optical technique together with electronic instrumentation and custom developed software, it is possible to quantify all traditional hairiness paramcters (i.e. hairiness $(H)$, its coefficient of variation (CVH) and standard deviation $(\mathrm{sH})$ ) used in the lextile industry, as wcll as determine several olhers, such as mean deviation coefficient $(U)$, deviation rate (DR) and its integral (IDR).

The overall goal of the current project is to develop an integrated automatic yarn system characterization: evenness analysis determination using capacitive sensors, hairiness analysis using coherent optics technique and finally, image processing for yarn production characteristics.

2007 Elsevier B.V. All rights reserved.

Keywords: Yarn hairiness; Optical analysis; Signal processing
\end{abstract}

\section{Introduction}

Yarn quality depends highly on the level of yarn homogeneity, in particular the unevenness, which quantifies the mean variation in linear density of a strand or part of it $[1,2]$. These irregularities are usually detected using capacitive sensors, which, in commercial equipments, perform yarn analysis in steps of $8 \mathrm{~mm}$. The integrated system being developed, Mass Parameterization System, version 2 (MPS2), uses the same technology, but performs an analysis on $1 \mathrm{~mm}$ sections [3]. This increase in resolution enables direct detection as most yarn irregularities occur on length scales between 1 and $4 \mathrm{~mm}$.

In addition to irregularities, another important feature of yarn is hairiness (released yarn fibres). Hairiness can also significantly affect the appearance of fabrics for certain applications. Its measurement is usually undertaken using optical sensors for samples over an interval of $1-20 \mathrm{~mm}$, in the most common com-

\footnotetext{
* Corresponding author.

E-mail address: vcarvalho@dei.uminho.pt (V. Carvalho).
}

mercial equipment. We can configure MPS 1 to analyze sample sections between 1 and $10 \mathrm{~mm}$, but prefer to focus on $1 \mathrm{~mm}$ lengths for higher resolution. Using capacitive and optical sensors measurements together with signal processing techniques, it is possible to determine all important yarn parameters for evaluating yarn quality.

The final goal is to permit the increase of quality requirements over determined thresholds by the yarn producer. The use of this solution will permit a significantly higher level of yarn homogeneity to be routinely obtained.

\section{Theoretical considerations}

As referred above, an important yarn characteristic, which greatly influences the appearance of fahrics is hairiness. This phenomenon appears as a result of released fibres over the strand. Fig. 1 presents an example of hairiness.

Measurement of yarn mass and hairiness allows the determination of several yarn statistical parameters through the application of signal processing techniques. Although, commercial equipment statistically quantify hairiness using standard 


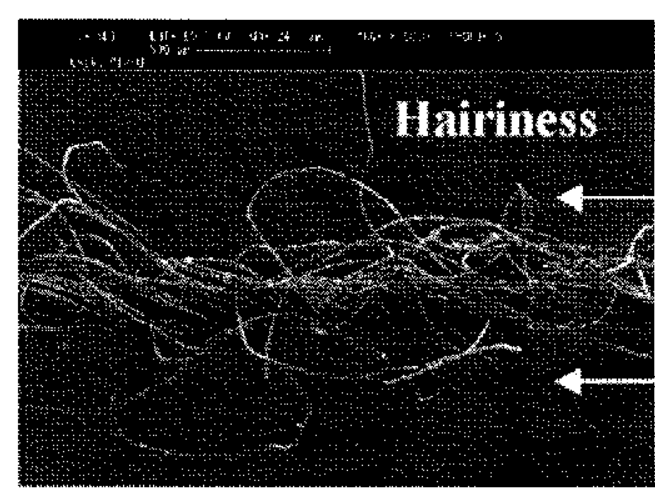

lïg. 1. Hairiness over a yarn.

deviation $(\mathrm{sH})$ and coefficient of variation $(\mathrm{CVH})$ all the other parameters quantified in mass measurements can be applied to hairiness, namely mean deviation coefficient $(U)$, deviation rate (DR) and its integral (IDR) $[4,5]$.

In general, commercial equipment use signal processing techniques, over the measured signal, based on fast Fourier transform (FFT). The system under development, MPS2, also applies fast Walsh Hadamard transform (FWHT) [3] and fast impulse frequency determination (FDFI) $[3,6]$ techniques.

Our method of hairiness analysis employs a light emitter (laser)/receiver (photodiode) pair with the addition of an optical setup to analyze yarn hairiness using a coherent optical signal processing technique based on Fourier optics (1) [4]. Consider a coherent plane wave, which illuminates an object and then propagates through a lens towards its principle focal plane on the far side. Fourier optics implies that the electric field distribution in the focal plane of the lens is the Fourier transform of the ficld distribution in the object plane. The lower spatial frequencies of the image will be concentrated close to the optical axis while the higher spatial frequencies will be located further from the optical axis. Mathematically, the field distribution in the principal focal plane of the lens will be given by the expression

$F\{g\}=\iint_{-\infty}^{\infty} g(x, y) \mathrm{e}^{-j 2 \pi\left(u_{x} x+w_{y} y\right)} \mathrm{d} x \mathrm{~d} y$

where $g(x, y)$ describes the field distribution in the object plane and $v_{x}$ and $v_{y}$ are the respective spatial frequencies $\left(\mathrm{m}^{-1}\right)$ along the $x$ and $y$ directions. The characteristic spatial frequency associated with an object of size $d$ is given by,

$v \approx \frac{\lambda f}{d}$

where $v$ is the spatial frequency $\left(\mathrm{m}^{-1}\right), \lambda$ the wavelength $(\mathrm{m})$ and $f$ is the focal distance $(m)$ of the Fourier lens.

Sharp transitions from light to dark in the object plane will result in high spatial frequencies, whereas the nearly uniform background illumination possess only very low spatial frequencies. By placing a small round opaque filter centred on the optical axis in the Fourier plane, we can block the low frequency background information while letting pass the information about the sharp transitions from light to dark that occur at the yarn boundaries and individual fibres that give rise to hairiness (Fig. 2).

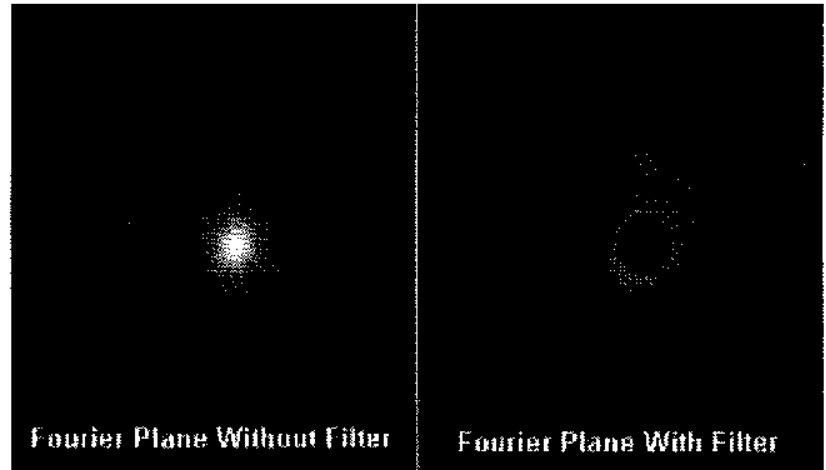

Fig. 2. Application of the high-puss spatial filter in the Fourier plane.

When imaged by a second lens this high-pass filter setup results in a dark and bright image, where the bright signal contains information about yarn hairiness (Fig. 3), that is converted by a photodiode, into a proportional current intensity $[4,5]$.

\section{Measurement setup}

Measurement of hairiness requires two distinct parts of hardware, electronic and optical. The electronic hardware employs, as a receiver, a photodiode (S1227-1010BR) from Hammamtasu $^{(1)}$. Some of its key characteristics are: a measurement area of $10 \mathrm{~mm} \times 10 \mathrm{~mm}$, sensitivity for the emitter used (He-Ne Laser emitting at a wavelength of $632.8 \mathrm{~nm}$ ) of $0.39 \mathrm{~A} / \mathrm{W}$, a maximum dark current of $50 \mathrm{pA}$, a shunt resistance of $2 \mathrm{G} \Omega$ and a terminal capacitance of $3000 \mathrm{pF}$. A conditioning circuit was designed [4] featuring a high precision current to

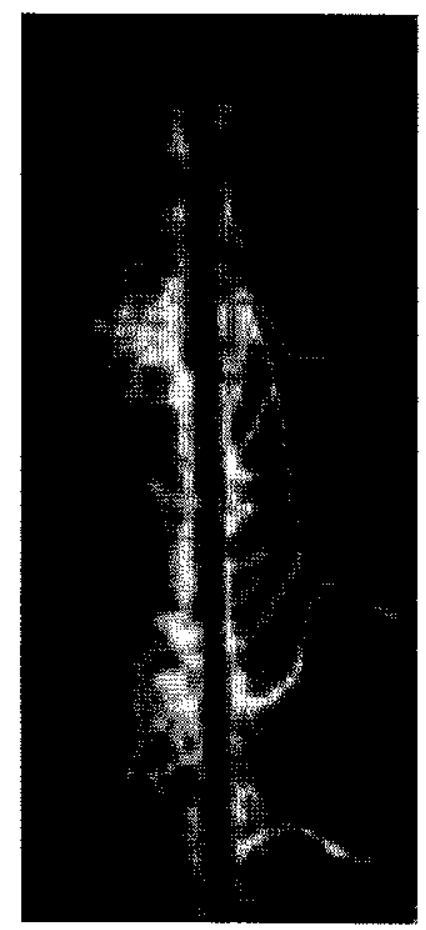

Fig. 3. Example of an image resulting from coherent optical signal processing. 


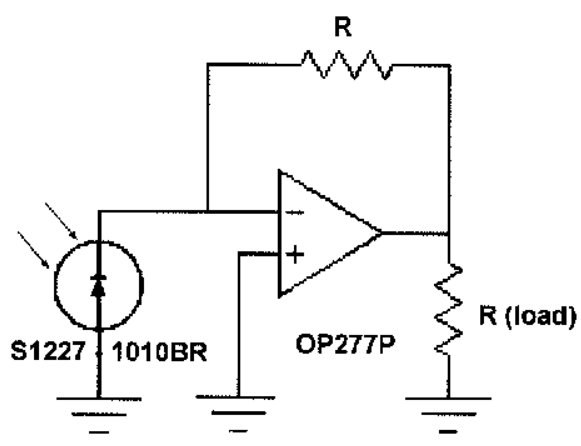

Fig. 4. Measurcment electronic hardware.

voltage converter, based on a Burr-Brown operational amplifier OP277P (Fig. 4) [71.

As the operational amplifier offset and photodiode dark current are extremely reduced, they can be neglected, compared to the signal's magnitude. Provided that saturation of either the photodiode or the operational amplifier can be avoided, we can obtain a direct proportionality between the photodiode current and the output voltage by (3).

$V_{R_{\text {load }}}=-R I_{\text {pholodiode }}$

The output of the operational amplifier is connected to an analogue channel of the data acquisition board (PCI-6024E from National Instruments) and the software developed in LabView (B) acquires and processes the data [8]. Fig. 5 shows the optical system developed for hairiness determination [4,5].

As mentioned above, this setup is designed to greatly increase the contrast in the optical signal due to yam hairiness. The yarn to be studied is placed in the object plane. A custom fabricated spatial filter $(F)$ is placed in the Fourier plane of $L 3$, to process the image, allowing only the high spatial frequencies in the image to propagate further. Essentially, this is a high-pass spatial Fourier filter [9-11]. This highlights the contours of the edges of yarn and associated hairs, while simultaneously eliminating the constant background associated with the portion of laser beam that was not obstructed by the sample. Through this method, a much higher portion of the processed optical signal is associated with the presence of hairs on the yarn. However, there is still some signal that comes from the contours of the yarn itself as well as light scattered by the optical elements. To characterize this "background signal", we eliminate the hairiness of the yarn either by wetting it with water or quickly passing the yarn through an open flame to burn the "hairs". When placing the wet or burned yam in the object plane we obtain a "background signal", which we designate by voltage without hairiness $\left(V_{\text {wh }}\right)$.

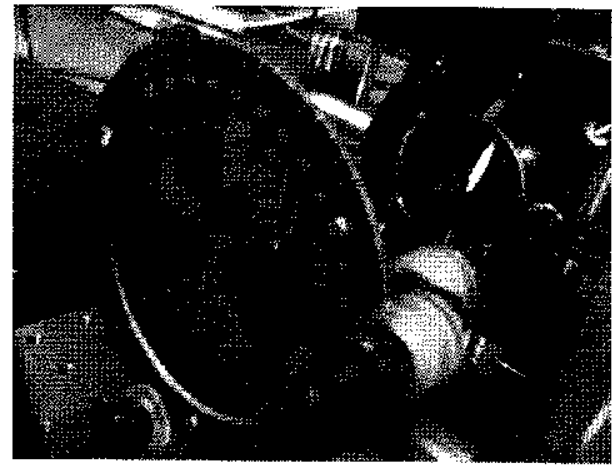

fig. 6. Linear polarizer used.

Determination of the variation of hairiness in comparison to the average hairiness value is obtained through the expression (4) $[4,5]$.

$\operatorname{Var}_{\text {Hairiness }}(\%)=\frac{X_{\mathrm{i}}-V_{\mathrm{m}}}{V_{\mathrm{m}}-V_{\mathrm{wh}}} \times 100$

where $V_{\mathrm{m}}$ is the hairiness mean output voltage $(\mathrm{V}), X_{i}$ the hairiness sample voltage (V) and $V_{\mathrm{wh}}$ is the reference signal produced by the yarn without hairiness (V).

Using the optical measurement setup as presented in Fig. 5. a fair amount of background light was still incident on the photodiode, probably due to the use of uncoated optical elements. We found, however, that we could drastically reduce this background signal by using a linear polarizer from Spindler \& Hoyer (Fig. 6) crossed results in a nearly background free signal, significantly increasing the dynamic range of the hairiness measurements.

\section{Results}

In order to validate the application of this method, we present the results for several yarns with different linear masses covering the range that is commonly used in the textile industry.

We analyzed six different $100 \%$ cotton yarns with different linear masses (from about 20 to $295 \mathrm{~g} / \mathrm{km}$ ) and a seventh sample formed by twisting two samples of one of these yarns $\left(96.88 \mathrm{~g} / \mathrm{km}, x^{2}=193.76 \mathrm{~g} / \mathrm{km}\right)$. The tests were performed both with and without a polarizer. We also measured the signal levels for yarn as manufactured (i.e. with hairiness) and yarn without hairiness, for reference. This reference of yarn without hairiness was obtained using two methods: water droplets to smooth the hairs and an open flame to burn the hairiness. These three signals, yarn as manufactured and the two references, were obtained using the same yarn samples. Different segments of each type of yam were analyzed and the average was calculated.
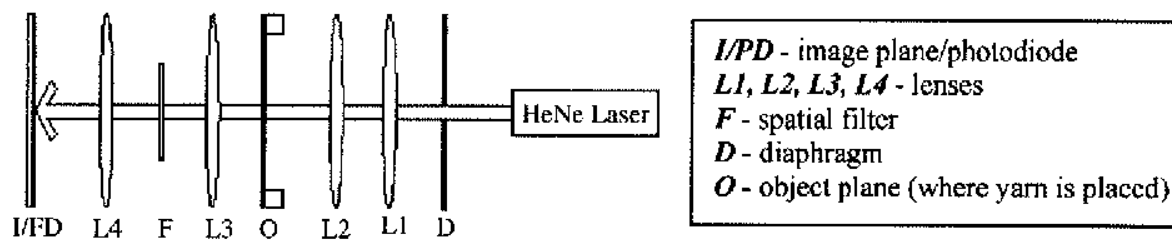

Fig. 5. Experimental setup of the optical system. 


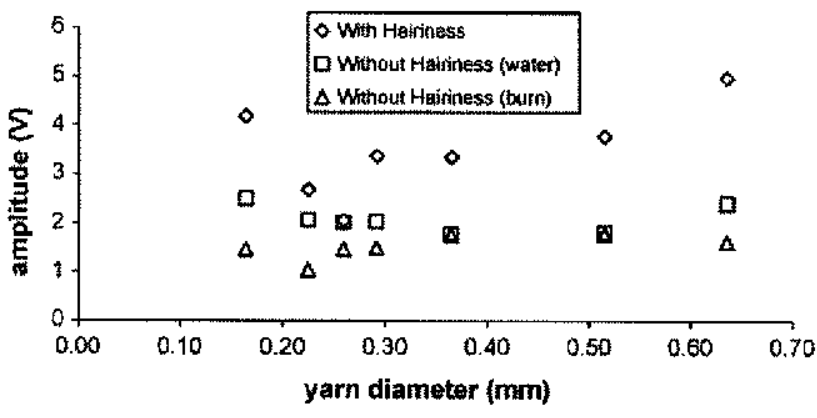

Fig. 7. Results obtained with polarizer.

Using the polarizer the output voltage without any yarn present was $0.14 \mathrm{~V}$, using a resistance of $1052 \mathrm{k} \Omega$ in the $I-V$ converter, which results in a sensibility of $1.052 \mathrm{~V} / \mu \mathrm{A}$. Fig. 7 presents the results obtained.

Without the polarizer the output voltage without any yarn was $0.79 \mathrm{~V}$, using a resistance of $45 \mathrm{k} \Omega$ in the $I-V$ converter, which causes a sensibility of $0.045 \mathrm{~V} / \mu \mathrm{A}$. The sensitivity was reduced due to the higher amount of signal without the polarizer (about 20 times), to avoid the saturation of the $I-V$ converter. Fig. 8 presents the results obtained.

Comparing the results obtained with and without the polarizer, it can be verified that the signal level with hairiness is well above the references values (with and without polarizer). However, it is only possible to distinguish a difference in the reference values (water and bum methods) if a polarizer is used. In general, burning results have a lower reference value. As mentioned above, the presence of the polarizer significantly improves the dynamic range for the measurements allowing us to detect the small differences between the two methods of creating a reference yarn.

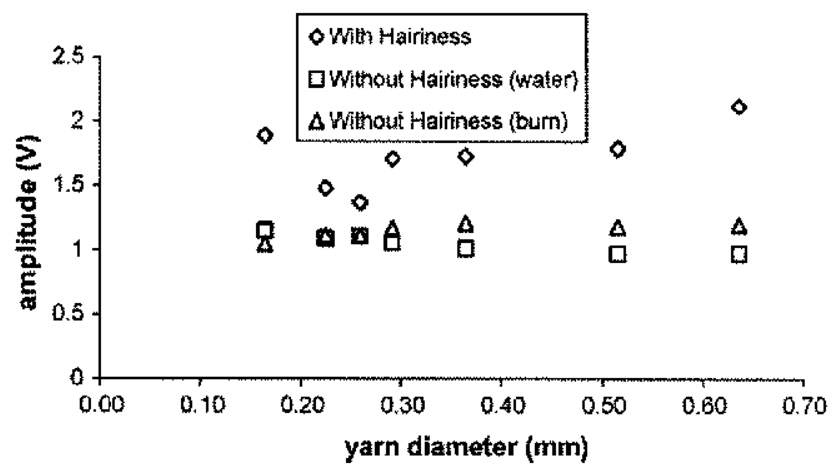

Fig. 8. Results obtained without polarizer.

During these tests, several pictures were taken (Figs. 9 and 10). It is important to state that images acquired using the polarizer required a significantly longer exposure time as the overall signal level is strongly reduced by the polarizer. Comparing these images, it is clear that the polarizer significantly reduce the background signal level.

\subsection{Analysis of results with polarizer}

Analysing Fig. 7, it is possible to verify that the least hairy yarm has a diameter of $0.26 \mathrm{~mm}$; the signals with and without hairiness being the closer together for this yarn. The yarn with the greatest amount of hairiness is that with a diameter of $0.64 \mathrm{~mm}$. It is also verified that the yarns with diameters of 0.36 and $0.52 \mathrm{~mm}$ present very similar results in all analyzed levels. This happens because these yarns are exactly the same, but one is the duplication of the other. So, being the same yarn, with similar characteristics, the results are approximately equal, even for different linear masses. These results confirm that the increase
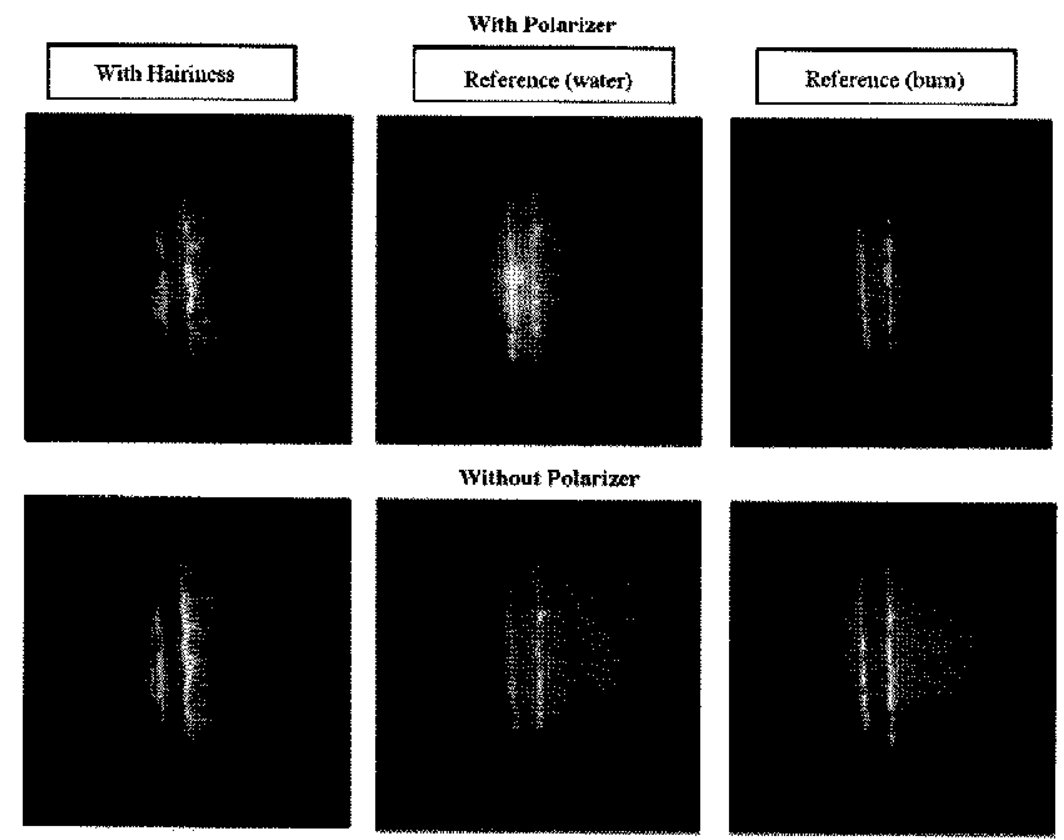

Fig. 9. Pictures obtained for a $100 \%$ cotton yarn with a linear mass of $295 \mathrm{~g} / \mathrm{km}$. 

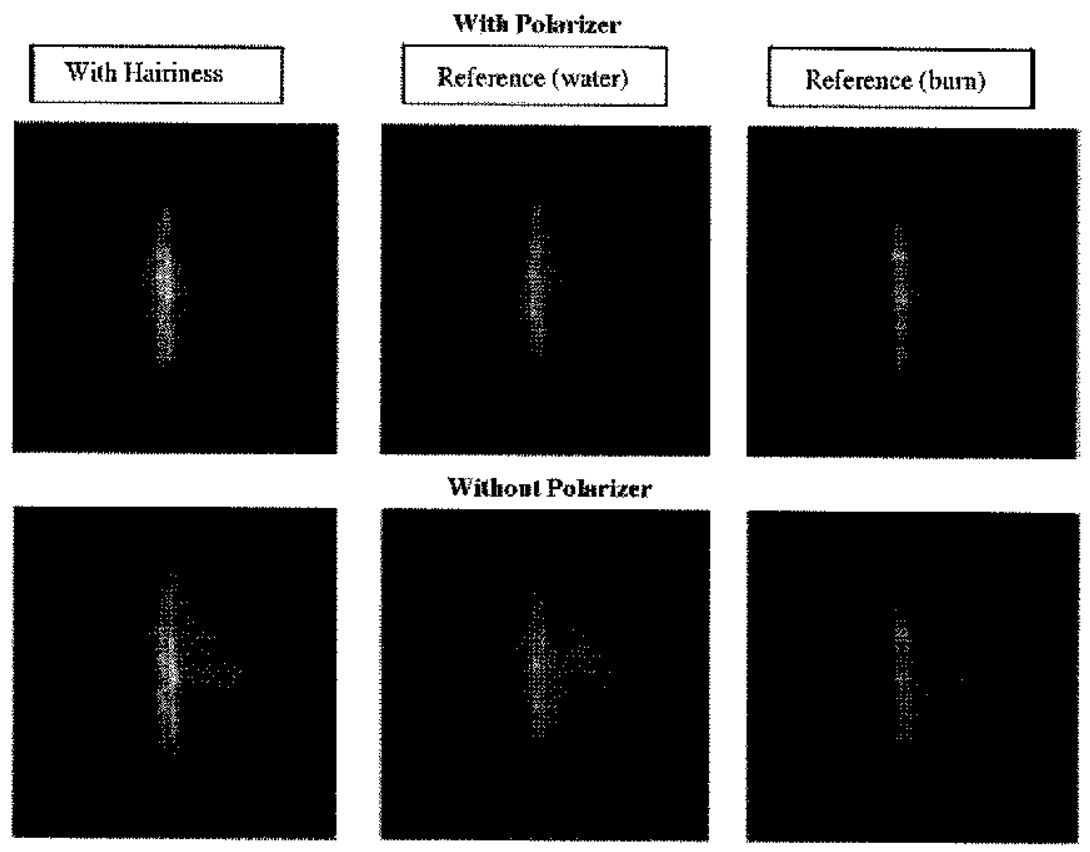

Fig. 10. Pictures obtained for a $100 \%$ cotton yam with a linear mass of $36.8 \mathrm{~g} / \mathrm{km}$.

of yarn diameter does result in an increase or decrease of signal. Rather the signal contribution the contours of the yarn depend only on the yarn border characteristics, which are similar in both samples.

Using the results obtained in Fig. 7, we studied the possibility of there existing a linear relationship between the yarn diameter and the reference levels (Fig. II). In fact, there is a complete lack linear correlation between the reference values and yarn diameter, as evidenced by the low $R^{2}$ values obtained. The signal that is received by the photodiode depends on the sharpness of the transition at the yarn borders, which is not directly related to the yarn diameter. So, a yarn with a larger diameter does not necessarily result in a higher reference level than a yarn with a smaller diameter. However, a thicker border does result in a higher signal. This border transition is strongly related to the level of yarn regularity in particular, regarding yarn defects (thin and thick points and neps). A thick point or a nep causes a thicker border, while a thin point causes a thinner border. Looking at Fig. 11, it is also obvious that the reference methods are not completely consistent. In the following sections, we make extensive comments as to what is responsible for this inconsistency.

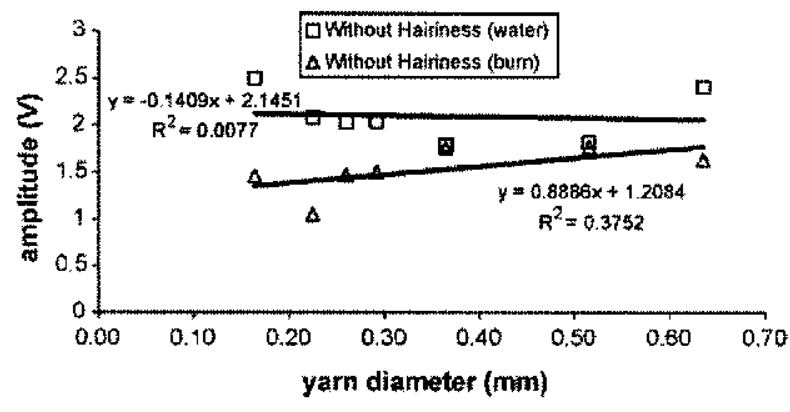

Fig. 11. Variation of yarn reference levels with the yarn diameter.

\subsection{Reference methods comparison}

Considering the burn method to create a reference it can be stated that:

(a) The yarn sharpness of the transition at the borders can vary depending on the amount of time that the yarn was exposed to the flame (Fig. 12). This figure presents images obtained without a polarizer for a sample of $100 \%$ cotton yarn with a linear mass of $295 \mathrm{~g} / \mathrm{km}$. The right most image corresponds to a yarn with hairiness. The other two images comespond to yarn that was passed through an open flame either relatively quickly (left most image) or more slowly (centre image).

(b) The burning process we used is rather difficult to control, especially for yarns with lower linear mass, which burn extremely easily. It is possible that surplus yarn material near the core is eliminated, changing the yarn's characteristics, as appears to be the case in Fig. 12, centre picture.

(c) Finally, the burning process employed could cause new hairiness with reduced length, as a result of the yarn fibres near the surface breaking if small segments were burned (Fig. 13, right picture). Fig. 13 presents pictures obtained without a polarizer for a sample of $100 \%$ cotton yarn with a linear mass of $193.76 \mathrm{~g} / \mathrm{km}$, with hairiness (left picture) without hairiness, using the water reference method (centre picture) and the burn reference method (right picture).

Considering the water reference method it can be stated that:

(a) It increases slightly the scattering level of yarn due to the water's dielectric properties (Fig. 13, centre picture), where it can be seen that in the yam interior the scattering is higher in comparison to the picture with hairiness (normal yarn). 

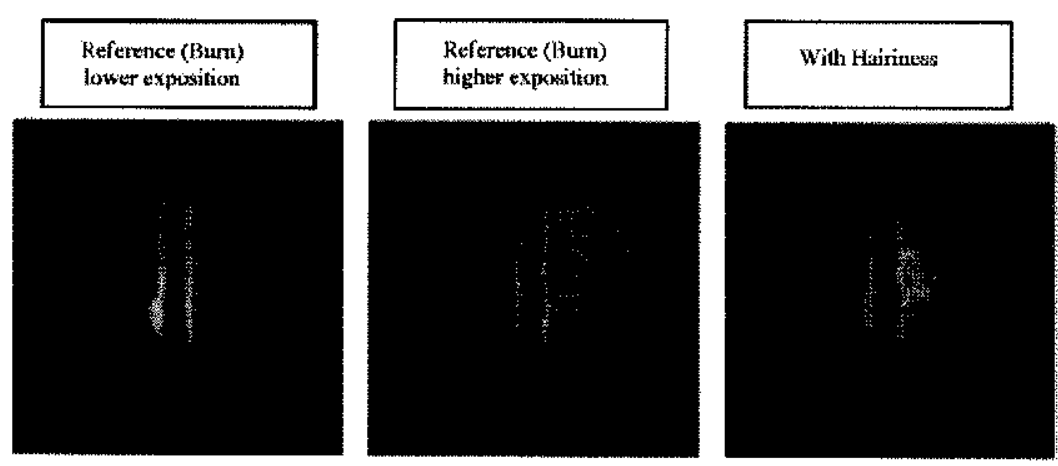

Fig. 12. Influence of burn in the yarn tonality.
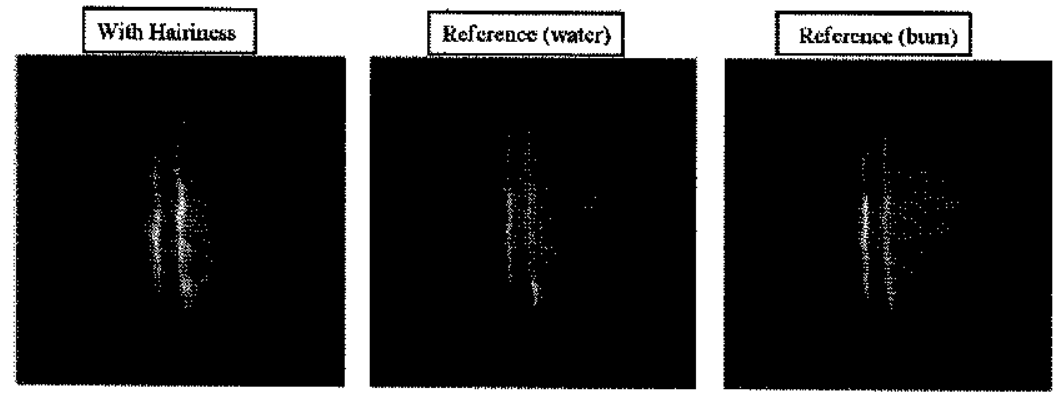

Fig. 13. Influente of reference methods in the yarn.

However, this increase is not very significant, relative to the signal, which comes from the yarn borders, especially in the case when a polarizer is used. This is supported by the results obtained with the yarn of $0.26 \mathrm{~mm}$ diameter (Fig. 7), which is a highly regular yarn possessing little or no hairiness or defects. In this yarn, the levels obtained with the reference method of water are very similar to those obtained for yarn with hairiness, implying that the water does not appreciably increase the signals in this case.

(b) The water method is a simple process to implement and does not cause new hairiness. However, one must be careful to perform the measurements before the yarns starts to dry.

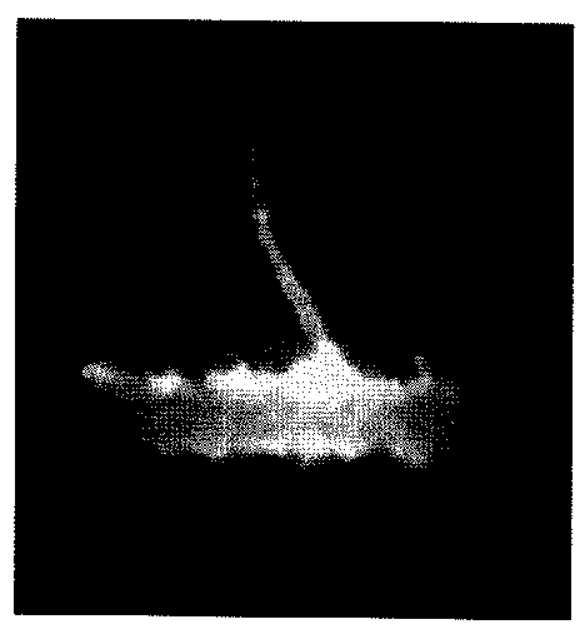

Fig. 14. Hair isolation.
Given the above considerations, we feel that the water method is more reliable to obtain the needed reference signal.

\subsection{Hairiness measurement length calibration}

This study was performed isolating one single hair in the yarn with a diameter of $0.64 \mathrm{~mm}$ (Fig. 14).

To isolate the hair we used silicone to eliminate all the other yarn hairs. Silicone was used instead of water to avoid the problem associated with drying, which would have allowed undesired hairiness to appear during the extended test duration.

Afterwards, the isolated hair was stretched and oriented perpendicular to the yarn. However, to ensure that the signal received by the photodiode was only due to the hair itself, we built a "window" using an opaque card that was placed in front of

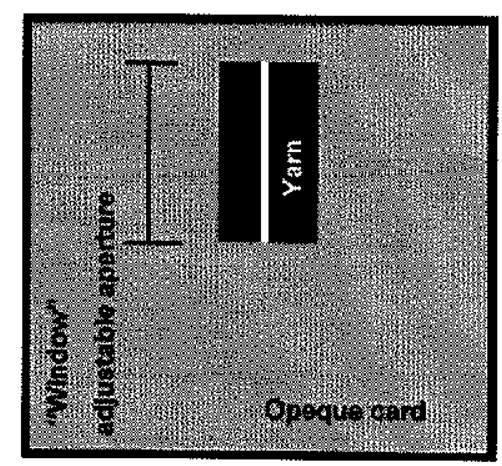

Fig. 15. Window aperture in the maximum position. 


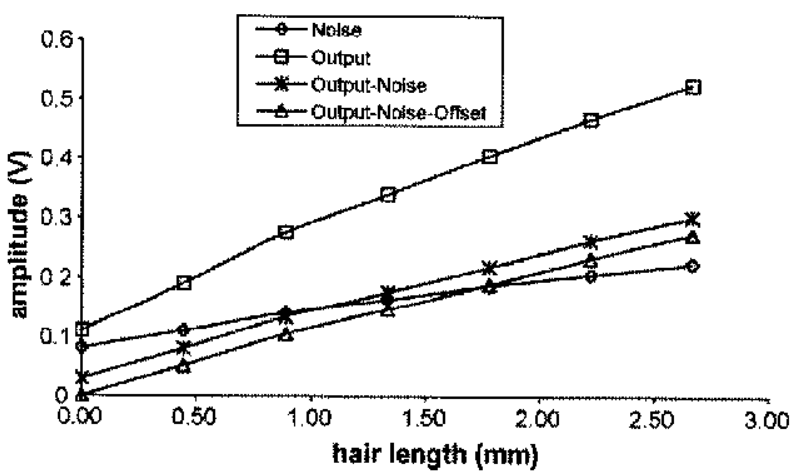

Fig. 16. Measured results for system calibration.

the photodiode. The "window" was positioned to block the signal due to the yarn's borders which became somewhat enhanced due to the light scattering from the silicone which has a high refractive index. The "window" used had an adjustable aperture, to allow us to measure the variation of the output voltage as a function of the hair length (Fig. 15).

The hair had an actual length of $2.67 \mathrm{~mm}$. After imaging by the lenses the projection of the hair on the photodiode had a length of $1.50 \mathrm{~mm}$. This means that a $44 \%$ reduction of the actual hair length occurred due to the optical elements needed to image the signal on the photodiode.

The measurement process was realized by reducing the aperture in steps of $250 \mu \mathrm{m}$. Starting with the window fully opened we gradually reduced the aperture until it was fully closed obtaining seven separate readings. Afterwards, the hair was taken out and the window was gradually opened to register the background signal at each aperture setting, which was then subtracted from the corresponding values obtained with the hair. The operational amplifier offset signal (value measured with no light signal) was also subtracted from all measurements. Fig. 16 presents the results obtained.

Afterwards we looked for a linear correlation for the tinal curve (output-noise-offset) (Fig. 17). The correlation coefficient $\left(R^{2}\right)$ is extremely close to the unity and we can reliably claim that

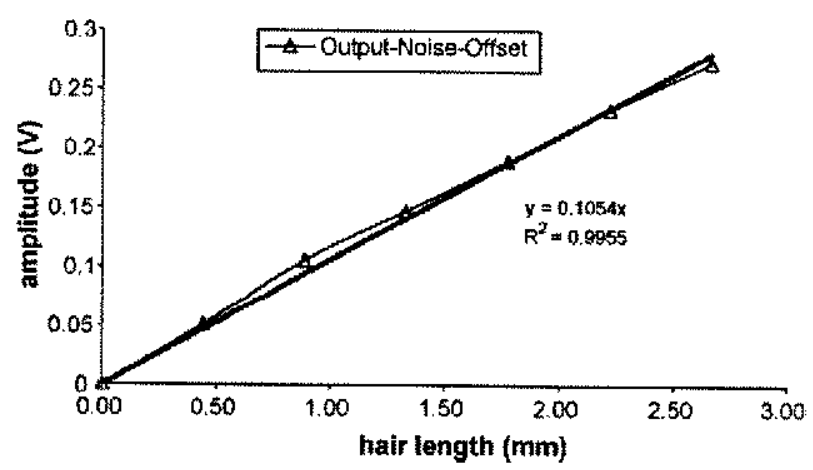

Fig. 17. Lincar correlation for final output

the signal obtained from a single hair is directly proportional to its length. In fact the fit allows us to calibrate the system. In this case, the output signal $(y)$ is related to the hair length $(x)$ by the expression $y=0.1054 x$, which implies that for each millimetre of hair length, the output increases by $105.4 \mathrm{mV}$ for the gain used in these tests.

Fig. 18 presents yarn pictures that were taken using an electron microscope with a scale of $50 \mu \mathrm{m}$ corresponding to a third of picture length.

On immediately notices that the individual fibres are not round, but rather ribbon-like with a cross-section that can be much smaller in one direction. However, the linear mass of each fibre should be approximately uniform. Our method of detecting hairiness is not sensitive to the actual fibre diameter (as would be the case in methods based on diffraction). So, we believe that our method gives a reliable estimate of the linear mass associated with the hairiness.

Regarding the variation of hair diameter (fibres) between the yarns tested and over the same yarn, as they present very small variations (only a few microns) (Fig. 18), their influence comparalively to the influence of hair length, could practically be neglected. So, the study performed can be used as a convenient reference.
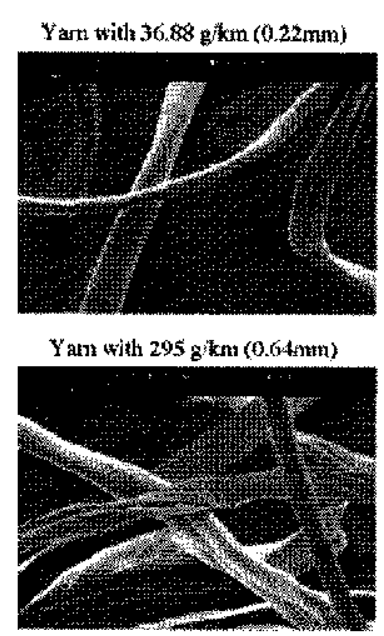

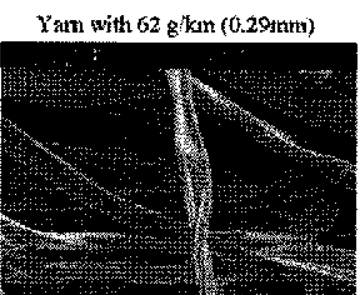

Yam with $19.67 \mathrm{~g} / \mathrm{km}(0.16 \mathrm{mun})$

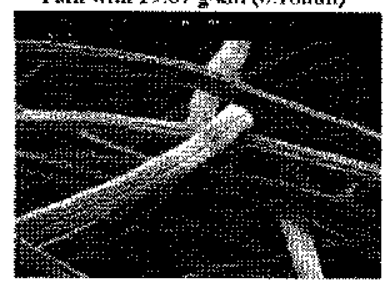

Yam with $49.17 \mathrm{~g} / \mathrm{kan}(0.26 \mathrm{~mm})$

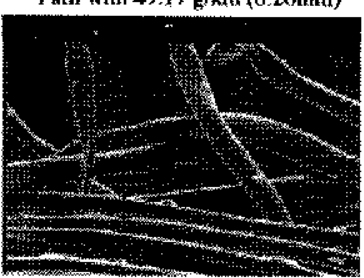

Yam with $48.44 \mathrm{~g} / \mathrm{km}(0.26 \mathrm{~mm})$

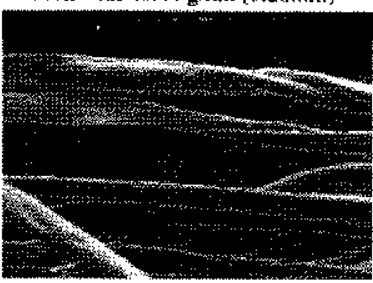

Fig. 18. Yarns electron microscope pictures. 


\section{Conclusions and future work}

The measurement method used for hairiness determination showed satisfactory results. There is a significant variation between the reference signal (yam with no hairiness) and the yarn as manufactured signal (with hairiness).

The inclusion of the polarizer in the optical setup reduced drastically the background light level, increasing the signal's dynamic range and consequently the measurement precision. Using the polarizer, the reference levels (water and burn) can be distinguished, with the burn method generally presenting a lower reference value.

The water reference method appears to be more reliable and the small extra scattering caused by water practically does not influence the normal yarn level, due to high percentage of signal from the yarn borders. We verified that there is no linear relationship between yarn diameter and the reference values.

By holding a hair and using a window aperture, we have confirmed that the signal output is directly proportional to the length of the hairs causing the signal.

With these results, we have taken an important step towards achieving the overall goal of developing an integrated yarn quality testing equipment with integrated capacitive and optical measurements as well as image processing for measuring yarn production characteristics. This will establish a new and efficient apparatus to control yarn production for required quality definitions.

\section{Acknowledgment}

The authors are grateful to the Portuguese Foundation (FCT) for funding through the scholarship (BD/19028/2004).

\section{References}

[1] B.C. Goswami, J.G. Martindale, F.L. Scandino, Textile Yarns-Technology, Structure and Applications, John Wiley and Sons, New York, 1977.

121 J.S. Neves. A irregularidade dos fios têxteis, sua origem, mediçāo e análise, Oporto, 1968.

[3] V. Carvalho, Parametrização de Fio Têxtil Baseada na Análise de Massa, MSc Dissertation, Minho University, Guimarães, 2004.

[4] V. Carvalho, P. Cardoso, M. Belsley, R. Vasconcelos, F. Soares, Determination of Yarn Hairiness Using Optical Sensors, EUROSENSORS XX, Gothenburg, Sweden, 17-19 September, 2006.
[5] V. Carvalho, P. Cardoso, M. Belsley, R. Vasconcelos, F. Soares, Development of a Yam Evenness Measurement and Hairiness Analysis System. IECON'06, Paris, France, 6-10 November, 2006.

[6] J.L. Monteiro, C.M. Couto, Pulse Frequency Calculation and Estimation in Yarn Evenness Analysis, IECON'95, Orland, USA, 6-10 November, 1995.

[7] S. Franco, Design wilh Operational Amplifiers, third ed., Mac-Graw Hill, Iowa, 2001.

[8] url: www.ni.com.

[9] J.W. Goodman, Introduction to Fourier Optics, McGraw-Hill, Greenwood Village, 1996.

[10] E.G. Steward, Fourier Optics: An Introduction, Dover Publications, New York, 2004

[11] P.M. Duffieux, The Fourier Transform and its Applications to Optics, second ed., John Wiley \& Sons, New York, 1983.

\section{Biographies}

Vitor Carvalho received his degree in industrial electronics engineering in the option of telecommunications and industrial informatics, in 2002 and $\mathrm{MSc}$ in industrial electronics, in the option of automation and robotics in 2004, both from Minho University, Portugal. At present, he his preparing for $\mathrm{PhD}$ in industrial electronics, which covers the subject presented here while working as lecturer, since 2005 , at IPCA. lfis main fields of interest are data acquisition and signat processing.

Paulo Cardoso received his degree in applied physics, in 2002 from Porto University, Portugal. Actually, he is MSc student in biomedical engineering. His main fields of interest are the optical signal processing and non-linear oplics.

Michael Belsley obtained his PhD degree in physics from the University of Colorado at Boulder in $\mathbf{1 9 8 6}$. He then worked at the California State Unjversity in Long Beach, Oxford University and the University of Oregon before coming to Minho University in Braga Portugal where he has lectured as an associate professor of physics since 1992. His main fields of interest are laser spectroscopy and non-linear optics.

Rosa M. Vasconcelos received her degree in textile engineering, in 1984 at Minho University, Portugal. In 1993, she obtained her PhD in engineering-textile tcchnology and chemistry on the speciality of textile technology, in Minho University. Since 2005, she is working as associate professor, in the Textile Engineering Department of Minho University. Her fields of interest are tcxtile processes and industrial automation.

Filomena $\mathbf{O}$. Soares received her degree in chemical engincering, in 1986 at Porto University, Portugal. In 1997, she obtained her PhD in chenical engineering from Porto University. Since 1997, she is working as assistant professor, in the Industrial Electronics Department of Minho University. Her fields of interest are process modelling and control and process automation. 